\title{
Influence of photoperiod and temperature on oocyte growth in the semelparous polychaete Nereis (Neanthes) virens
}

\author{
Peter J. W. Olive ${ }^{1, *}$, Simon W. Rees ${ }^{1,2}$, Ali Djunaedi ${ }^{1,2}$ \\ ${ }^{1}$ Department of Marine Sciences and Coastal Management, University of Newcastle upon Tyne, Newcastle upon Tyne \\ NE1 7RU, United Kingdom \\ ${ }^{2}$ Seabait Ltd, Woodhorn Village, Ashington, Northumberland NE63 9NW, United Kingdom
}

\begin{abstract}
Environmental factors influencing the rate of oogenesis in the seasonal cycle of the semelparous polychaete Nereis (Neanthes) virens Sars have been investigated in specimens reared under commercial conditions (concrete tanks under natural light supplied with a mixture of power station heated and ambient sea water to maintain ca $18^{\circ} \mathrm{C}$ all year round). The rate of oocyte growth is strongly influenced by the external photoperiod and the responses to static $24 \mathrm{~h} \mathrm{LD} \mathrm{(light-dark)} \mathrm{cycles} \mathrm{have} \mathrm{been} \mathrm{investigated.}$ Oocyte growth is more rapid when specimens are exposed to a $24 \mathrm{~h} \mathrm{LD}$ cycle in which the photophase is below a critical value between 12 and $13 \mathrm{~h}$. The critical photoperiod transition in natural environments is therefore at the autumn equinox. $N$. virens are able to respond to transfer between LD 16:8 h and LD 8:16 h at all times of the year, which suggests the operation of a continuously consulted system of photoperiodic control. The rate of oocyte growth in competent specimens is a linear function of the number of LD 8:16 h cycles experienced. The critical photoperiod divides the solar year into 2 nearly equal periods, with the short day period (winter) favouring oocyte growth. There is a synergism between the effects of photoperiod and seasonally reducing temperature. During the calendar winter transition to LD 8:16 h or other LD cycles below the critical value initiates rapid oocyte growth whatever the temperature but in the calendar summer this only occurs if the external temperature is also reduced to $12^{\circ} \mathrm{C}$ or below. The response to photoperiod and temperature is moderated by internal factors and under commercial production systems elevated rates of oocyte growth can only be achieved in females that are about 1 yr old. The oocyte growth induced by exposure to LD 8:16 h light cycles and low temperature is similar to, but slightly less than, that induced by hormone deprivation, i.e. supra-oesophageal ganglion ablation. The results are discussed in relation to the control of seasonal cycles in Nereidae, the role of the endocrine system and in the context of the life history theory for long lived semelparous organisms with variable age at maturity.
\end{abstract}

KEY WORDS: Nereis (Neanthes) virens - Photoperiodism - Critical day length - Polychaeta Oogenesis Temperature - Seasonal reproduction - Semelparity - Nereidae

\section{INTRODLCTION}

All members of the polychaete family Nereidae are strictly semelparous, i.e. they breed only once per lifetime, which contrasts with the more usual iteroparous mode of reproduction in marine invertebrates. The nereid life history involves a progression from birth through a pre-adult phase of somatic growth, to a prematurational phase during which gametogenesis takes place. This culminates in a more or less marked somatic metamorphosis to the heteronereid condition, which is secondarily suppressed in some species.

•E-mail: p.j.w.olive@ncl.ac.uk
After completion of gametogenesis, a genetically predetermined death occurs either immediately after spawning or, in some cases, after a brief post spawning period during which males or females may engage in brood care. The pre-determined death can however be prevented by implantation of juvenile cerebral ganglia into maturing specimens (Golding \& Yuwono 1994). Although individuals are normally strictly semelparous and breed only once, reproduction at the population level is cyclic, usually with a periodicity of $1 \mathrm{yr}$. The average life span (generation time) is often more than 1 yr (less in smaller species) and there may be lunar/ semilunar components to the breeding cycle (Hauenschild 1960, Olive 1981). 
Since, in almost all Nereidae, the generation time (= mean average lifespan) is longer than the phase length of the overt reproductive cycle, there must be some mechanism to regulate not only when reproduction occurs but also to determine which members of the population become sexually mature at any time.

Nereis (Neanthes) virens has recently been introduced to commercial culture (Olive 1994) and, in the production system operated in the UK, the cultured animals are maintained at or near $18^{\circ} \mathrm{C}$ throughout the year to maximise the somatic growth rate. The average age at reproduction in natural populations of $N$. virens has been variously estimated to be between 2 and 7 or more years, according to local conditions (Bass \& Brafield 1972, Creaser \& Clifford 1982, Caron et al. 1993, Olive 1993, Desrosiers et al. 1994), yet, despite variation in the age at reproduction within and between populations, maturing individuals always breed in the spring during April or May. This pattern of synchronised spring breeding has been maintained in the UK cultured populations over a period of $12 \mathrm{yr}$ although the generation time is reduced and may be only 1 yr (Olive et al. 1986, Olive 1998).

In natural populations, oogenesis may take over a year to complete within an individual worm (Brafield \& Chapman 1967, Creaser \& Clifford 1982, Desrosiers et al. 1985). Gametocytes accumulate in the coelom over a period of many months but grow relatively slowly until the onset of a more rapid oocyte growth phase during which the greater part of vitellogenesis is completed. The rapid growth of oocytes occurs from September to January (Brafield \& Chapman 1967, Fischer \& Hoeger 1993) but only in those members of the population that will breed and die in the following spring. During this rapid growth phase the oocytes double in diameter, from 80 to $160 \mu \mathrm{m}$, which, assuming the oocytes are spherical, represents a greater than 10-fold increase in volume; after this little further growth occurs. Mature oocytes in this species have a diameter between 170 and $200 \mu \mathrm{m}$ and the final stages of egg maturation involve changes in oocyte structure, most noticeably through the development of a prominent cortex to be involved in post fertilisation jelly coat release (Dhainaut 1984). The final stages of maturation are also accompanied by somatic changes which represent a partially suppressed epitoky (Clark 1961, Schroeder \& Hermans 1975). At the time of spawning, male Nereis (Neanthes) virens swarm into the water column, but females remain in their burrows (Brafield 1967. Desrosiers et al. 1994).

Preliminary observations made under commercial conditions suggested that the external photoperiod could influence the time of maturation of Nereis (Neanthes) virens (Djunaedi 1995), but the initial experiments were constrained by the commercial procedures. We have now proceeded to a systematic investigation of this phenomenon to take advantage of the opportunity provided by the culture system to investigate populations of known age and parentage. We have also considered the possible involvement of the endocrine system in the transduction of environmental signals in this group of animals (Bentley \& Pacey 1992, Olive 1997).

\section{MATERIALS AND METHODS}

Sources of experimental animals and conditions of culture. Specimens used in these experiments were obtained from artificial fertilisations of commercially farmed Nereis (Neanthes) virens initially derived by cross breeding populations from a number of locations in the United Kingdom. They were reared at the premises of Seabait Ltd in warmed seawater (ca 34\%) in a relatively narrow temperature range $\left(16\right.$ to $20^{\circ} \mathrm{C}$ ) by using power station coolant seawater mixed with natural seawater at ambient temperature in varying proportions during the year ('farm conditions'). The age of all individuals was known and the animals used in each experiment were siblings. Prior to use, and during experiments when appropriate, specimens were fed dry pelleted food at a rate between 2 and $5 \%$ of wet weight biomass per day. In laboratory experiments any uneaten food was removed each day prior to the next feeding using a simple siphon device.

Experiment under farm conditions: A preliminary experiment is reported here that was carried out under farm conditions using animals selected from the commercial stock at an age of 15 mo and a mean weight of about $5 \mathrm{~g}$. Animals to be exposed to artificially short days were transferred to concrete tanks $\left(2 \mathrm{~m}^{2}\right)$ indoors at a density of $250 \mathrm{~m}^{-2}$. The tanks were supplied with running seawater at ambient temperature. The only light source was from tungsten bulbs connected to a timer switch over each light isolated tank. Others were exposed to natural ambient light in similar tanks outside receiving seawater from the same supply at ambient temperature. Over the course of the experiment the temperature varied between 12 and $16^{\circ} \mathrm{C}$ but was the same in the 2 groups of animals which differed only in the photoperiodic treatment they received.

Experiments under laboratory conditions: These experiments were carried out under laboratory conditions in plastic boxes $(80 \times 40 \times 30 \mathrm{~cm})$ fjlled with a fine sand sediment to a depth of $15 \mathrm{~cm}$ with a similar depth of water above this. The experiments were conducted either in static water using gravel filled air lift aeration units to maintain water quality or in plastic boxes supplied with seawater at a controlled temperature (for details see below) in a recirculation seawater system (Dryden Aquaculture Ltd-tencell system). Light was provided by fluorescent tubes. 
Environmental treatments and experimental design. All experiments were conducted in defined light dark cycles of 24 h duration, the convention used to describe these will be LD $x: y$ where $x$ is the duration in hours of light (photophase) and $y$ the duration of dark (scotophase)

Expt 1: Effect of the long day/short day transition on the rate of oocyte growth under farm conditions: A number of preliminary experiments were carried out under farm conditions; we have selected one of these for presentation here because it provided the first indication that changes in the external light dark cycle could bring forwards the time of rapid oocyte growth.

In this preliminary experiment, 1 yr old animals were selected in June and were transferred to the ambient seawater temperature regime (range 12 to $16^{\circ} \mathrm{C}$ ) which was cooler than that used for routine production. Approximately half the animals were placed under short photophase conditions (LD 8:16) while the other worms were exposed to the natural photoperiodic regime, which declines from a maximum of nearly $L D$ 17:7 in June to LD 12:12 at the autumn equinox (see Olive 1981). The 2 groups were subsequently sampled in October and the oocyte frequency distributions in individual animals determined. The results were then further collated as pooled oocyte frequency distributions for each treatment.

Following the initial experiment further experimentation was carried out under laboratory conditions to give a greater degree of control and to permit independent investigation of temperature and photoperiod.

Experiments in laboratory conditions: Animals were reared initially at ca $18^{\circ} \mathrm{C}$ under ambient (i.e. natural) photoperiodic conditions. They were then transferred to fixed $24 \mathrm{~h}$ LD cycles of different photophase duration. The animals were kept in plastic boxes in environmental cabinets fitted with timer controlled fluorescent tubes using air lift aeration to maintain water quality. A number of recirculation units were available so that a number of different constant temperatures could be maintained. Experiments were carried out at different times to investigate the modulating influence of real (calendar time) and environmental temperature on the photoperiodic responses.

Decerebration: A number of animals were subjected to supra-oesophageal ganglion ablation. The operation was carried out by anaesthetising the animals in $7 \%$ ethanol in seawater for 2 to $3 \mathrm{~min}$ and a portion of the prostomium was removed with iridectomy scissors. Three incisions at right angles to each other were made to create a flap of tissue which could be pulled forwards, the posterior incision being at the posterior of the prostomium. The supra-oesophageal ganglion (brain) sometimes moved with the flap of tissue and could then be easily removed in entirety, sometimes further connective tissue had to be removed before the brain could be excised. The 'decerebrated' animals showed remarkable ability to recover from this operation; they were allowed to recover from the anaesthetic and to heal in seawater prior to introduction to the experimental tanks and their subsequent survival was as good as that of other experimental animals. Nondecerebrated animals were similarly anaesthetised and all experimental animals were marked individually by clipping 1 or more parapodia to give each a unique code.

Bioassay of oocyte development (measurement and analysis). Coelomic biopsy: The stage of sexual maturity of individual worms was determined by the examination of samples of coelomic fluid containing developing gametocytes. Coelomic samples were taken from the animals using a modified Pasteur pipette or a $1 \mathrm{ml}$ syringe. In Expts 1 \& 2, but not subsequent experiments, the samples were placed in small plastic trays with $4 \%$ formaldehyde in seawater and kept for up to 1 mo prior to detailed analysis of oocyte frequency data Oocyte measurements and data analysis were carried out using a video camera connected to a compound microscope which fed the image to a colour monitor. PC Image Software (Foster Findlay Associates) allowed the accurate measurement of the oocyte images and the collation of a variety of statistical measures: length and breadth were routinely obtained for a minimum of 25 (more usually 50 oocytes) from each animal. In later experiments when the range of oocyte diameters was more uniform, a sample of oocytes was measured directly using a calibrated eyepiece graticule.

The coelomic samples were mixed with seawater and examined in the fresh state using a Leitz photolux microscope with graduated eyepiece and calibrated to $0.1 \mu \mathrm{m}$. In the case of samples containing oocytes 30 to 50 randomly selected oocytes were measured and the major diameter recorded.

Statistical treatments: The oocyte frequency distributions recorded by biopsy from the animals in the various experimental treatments present 2 aspects for analysis, (1) the change in oocyte size frequency within individual animals over time and (2) the changes in the degree of maturity among animals within an experimental group. The statistical analysis of these changes poses a particular problem because the oocyte frequency distribution in Nereidae is not independent of the mean, and, except when the mean diameter is close to either the maximum or minimum diameter, the oocyte frequency distribution within an individual female is not a normal one but is strongly skewed. Olive \& Garwood (1981) have discussed this problem for Nereis (Nereis) pelagica and Nereis (Hediste) diversicolor. We have adopted a number of solutions, though none may be ideal. 
In some experiments pooled oocyte frequency distributions were collated from the individual animals in each treatment. This was most appropriate when the mean oocyte diameter was greater than $120 \mu \mathrm{m}$ and the individual distributions were near to normality. The resulting oocyte frequency distributions, comprising the pooled measures of 50 oocytes from each animal, were compared using a parametric $t$-test for comparison of paired means, or by ANOVA and a posteriori analysis of the differences between means using SNK procedures (Sokal \& Rohlf 1995).

Individual females were also assigned to $10 \mu \mathrm{m}$ oocyte frequency categories according to the mean (or the mode) of the oocyte diameter frequency distribution. The frequency of females assigned to these $10 \mu \mathrm{m}$ categories provides an alternative nonparametric approach to the statistical treatment of the results in which the mean (or modal diameter) is used as a descriptor for the state of maturity of an individual female. When this was done the relative frequencies of animals classified by this descriptor were compared statistically using a G-test procedure and tested for heterogeneity (Sokal \& Rohlf 1995).

The progressive development of the eggs under different environmental regimes is also conveniently displayed as a curve of the cumulative percentage oocyte frequency distribution. This method of presentation gives a picture of the dynamic changes in oocyte size during oocyte growth and has been used to illustrate situations where different patterns of oocyte growth were observed in multiple treatments.

For clarity the rationale and design of individual experimental treatments is described prior to the presentation of the results.

\section{RESULTS}

\section{Exp1 1: Effect of the long day/short day transition on the} rate of oocyte growth under commercial conditions

Rationale. The experimental animals were selected in June from a single genetic broodstock reared under farm conditions which, at the beginning of the experiment, were at approximately the same stage of sexual maturity (mean oocyte diameter $<100 \mu \mathrm{m}$ ). They were kept under the same temperature and feeding regimes but were exposed to 2 different photoperiodic regimes, LD 8:16 and natural ambient light.

Observations. By October the oocytes of animals transferred to LD 8:16 were substantially larger than those of animals kept under ambient light conditions (Fig. 1). Animals exposed to LD 8:16 had completed the rapid phase of oocyte growth by October and subsequently became mature (and died) during December,

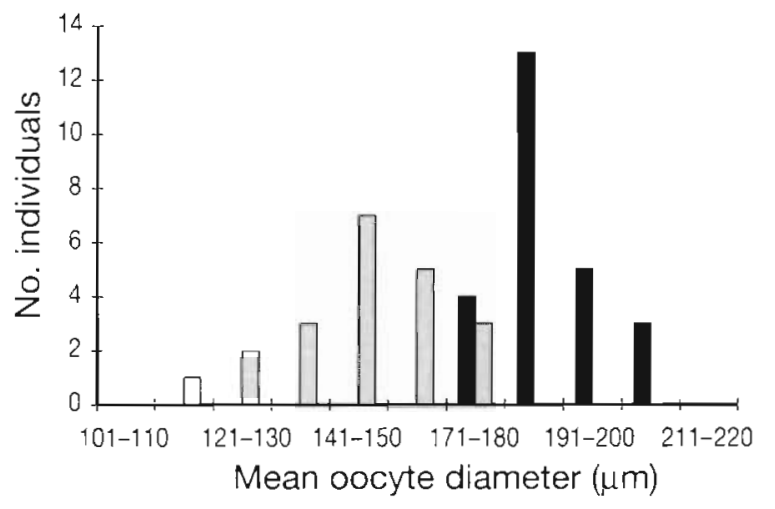

Fig. 1. Nereis (Neanthes) virens. Expt 1: Effects of a premature transition to 'short daylengths' i.e. to LD 8:16 from ambient photoperiod during the month of June (solid histograms) in comparison to animals experiencing a natural progression of daylength, i.e. LD 17:7 in June decreasing to LD 12:12 at the autumn equinox (hatched histograms). The histograms show the frequency of individuals in $10 \mu \mathrm{m}$ mean oocyte size categories. The category tor each individual was based on the mean diameter of 50 randomly selected oocytes from the

coelom. In each treatment 25 animals were examined

whilst the group under the ambient daylength cycle lagged several months behind and became mature only during the following spring.

We conclude that onset of the rapid phase of oocyte growth (vitellogenesis) must have been stimulated by the changed light conditions and that oocyte growth rate was higher in the animals subjected to the artificial LD 8:16 light regime from June than it was in those maintained in natural light. The partial shift in the time of breeding also provided valuable material for subsequent experiments by making available animals that were born in advance of the normal breeding season.

\section{Expt 2: Critical daylength effects}

Rationale and experimental design. The experiment was designed to detect and measure if possible the critical daylength in a static photoperiod response curve for the photoperiodic effect revealed by the previous experiment. Animals were kept at $17^{\circ} \mathrm{C}$ and exposed to the following static LD cycles: T2.1 = LD 9:15; T2.2 = LD $11: 13 ;$ T2.3 = LD 12:12; T2.4 = LD 13:11; T2.5 = LD 15:9 The animals were transferred to these different static LD cycles in June at an age of $15 \mathrm{mo}$ and when the ambient LD cycle to which they were previously exposed was LD 16:8. Coelomic biopsies were obtained in October, 5 mo after the start of the period of exposure to static photoperiods. Specimens were allocated randomly to the different treatment groups and assigned to $10 \mu \mathrm{m}$ oocyte diameter categories on the basis of the coelomic biopsies and the frequency of animals in these categories was monitored during the course of the experiment. 
Observations. A G-test analysis carried out in June (Table 1) showed that at this time there were no significant differences in the proportion of individuals in the oocyte size classes between experimental groups. By October however this situation had changed (Table 2); a $G$-test revealed a significant component of heterogeneity by treatments and further a posteriori testing (see Table 2) confirmed the presence of 2 separate subgroups. Those animals exposed to the photoperiodic treatments with the 3 shorter photophase lengths (LD $9: 15,11: 13,12: 12$ ) represented 1 homogeneous subgroup and those held in longer photophase lengths (LD 13:11, 15:9) formed another. There was significant heterogeneity between these 2 subgroups but not within them.

The mean oocyte diameter of the animals in the 3 'short' day treatments (LD 9:15, 11:13, 12:12) was greater than in the 'long' day treatments (LD 13:11, 15:9). Thus LD 9:15, 11:13 and12:12 have the same effect as exposure to LD 8:16 (Expt 1) while the treatments LD 13:11 and 15:9 have the same effect on oocyte growth rate as LD 16:8. The results suggest a critical photoperiod with the photophase between 12 and $13 \mathrm{~h}$ (critical scotophase between 12 and $11 \mathrm{~h}$ ).

\section{Expt 3: Evidence for continuous consultation of the photoperiod}

Rationale. The influence of photoperiod on animals is likely to be complex and any interaction between the external photoperiod and endogenous circaannual 'time' may modify the response to a given

Table 1. Nereis (Neanthes) virens. Distribution frequency for individual females classified into $10 \mu \mathrm{m}$ groups by mean oocyte diameter, in relation to photoperiodic treatment in June (cf. Table 2). The data were analysed for heterogeneity among groups using the $G$-statistic. The appropriate degrees of freedom were defined as $(a-1)(b-1)$ where $a=$ the number of oocyte size classes and $b=$ the number of light treatments. $G=6.482$ and since $\chi^{2 \text { crit(0.5.24)}}=36.41$ the data do not display significant heterogeneity at $p<0.05$

\begin{tabular}{lcccccc|}
\hline $\begin{array}{l}b=5 a=7 \\
\text { Diameter }\end{array}$ & L:D 9:15 & $11: 13$ & $12: 12$ & $13: 11$ & $15: 9$ & Total \\
\hline $71-80$ & & 1 & 4 & 2 & 2 & 9 \\
$81-90$ & 1 & & 3 & 3 & 4 & 11 \\
$91-100$ & 3 & 5 & 3 & 3 & 1 & 15 \\
$101-110$ & 5 & 6 & 6 & 6 & 6 & 29 \\
$111-120$ & 3 & 4 & 1 & 4 & 4 & 16 \\
$121-130$ & 6 & 3 & 1 & 1 & 2 & 13 \\
$131-140$ & 2 & 1 & 2 & 1 & 1 & 7 \\
$141-150$ & & & & & & \\
$151-160$ & & & & & & \\
$161-170$ & & & & & & \\
Total & 20 & 20 & 20 & 20 & 20 & 100 \\
\end{tabular}

Table 2. Nereis (Neanthes) virens. Distribution frequency for individual females classified into $10 \mu \mathrm{m}$ groups by mean oocyte diameter, in October (cf. Table 1). The data were analysed for heterogeneity among groups using the $G$-statistic. The appropriate degrees of freedom were defined as $(a-1)(b-1)$ where $a=$ the number of oocyte size classes and $b=$ the number of light treatments. Overall (all groups) $G=76.82 \chi^{2(r i t(0.5,20)}=31.41$. The value of $G$ is clearly greater than the critical $\chi^{2}$ and the data is heterogeneous. Subgroups photophase $9,11,12 ; G=10.42 \chi^{2 \text { crit|05.81 }}=15.51$ The $G$ value is not greater than the critical $\chi^{2}$ and there is no significant heterogeneity in this subset. Subgroups photophase 13, 15; $G=10.42 \chi^{2 \text { crit }(0.5 .5)}=11.07$. The $G$ value is not greater than the critical $\chi^{2}$ and there is no significant heterogeneity in this subset. The heterogeneous data set is therefore composed of 2 homogeneous subsets, those in which the photophase is $>12 \mathrm{~h}$ light and those in which the photophase is $12 \mathrm{~h}$ light or $<12$ h light

\begin{tabular}{lcrrrrr}
\hline $\begin{array}{l}b=5 a=6 \\
\text { Diameter }\end{array}$ & L:D 9:15 & $11: 13$ & $12: 12$ & $13: 11$ & $15: 9$ & Total \\
\hline $131-140$ & & & & 3 & 3 & 6 \\
$141-150$ & & & & 3 & 8 & 11 \\
$151-160$ & 1 & 6 & 4 & 6 & 11 & 28 \\
$161-170$ & 9 & 11 & 6 & 9 & 6 & 41 \\
$171-180$ & 7 & 6 & 13 & 5 & & 31 \\
$181-190$ & 6 & 1 & 2 & & & 9 \\
$191-200$ & & & & & & \\
Total & 23 & 24 & 25 & 26 & 28 & 126 \\
\end{tabular}

photoperiodic regime. Expt 3 was designed to test this possibility; animals were exposed to the critical photoperiodic transition from LD 16:8 and 8:16 at different times of the year. The working hypothesis was that a transition from LD 16:8 to LD 8:16 stimulates the onset of more rapid oocyte growth and that in order to be effective such a transition must follow a minimum period of exposure to long days LD 16:8.

The experiment was set up at the beginning of November 1996; the experimental animals were then about 11 mo old and did not have coelomic gametocytes. The experimental treatments used are represented diagramatically in Fig 2 in relation to real time; the animals in all the treatments were maintained at $17 \pm 1^{\circ} \mathrm{C}$ throughout.

Observations. The animals in all groups had begun to develop eggs by January regardless of the photoperiod they were experiencing. The ensuing rate of egg growth (diameter) was strongly influenced by the photoperiodic conditions. It was greatest in those animals maintained throughout the experiment under LD 8:16 (= group T3.7).

The progressive development of the oocytes in the 7 treatment groups is summarised as a set of cumulative percentage frequency curves in Fig. 3. Using this mode of representation accelerated oocyte growth shifts the curve to the right and the more uniform oocyte distributions are more steeply sigmoid. The treatment 


\begin{tabular}{|l|l|l|l|l|l|l|l|l|l|l|l|l|}
\hline Treatment key & \multicolumn{9}{|c|}{ Photophase 'Short' i.e. $=$ LD 8:16 } & \multicolumn{3}{|c|}{ Photophase 'Long' i.e. = LD 16:8 } \\
\hline Groups Months & Nov & Dec & Jan & Feb & Mar & Apr & May & Jun & Jul & Aug & Sep & Oct \\
\hline T3.1 & & & & & & & & & & & & \\
\hline T3.2 & & & & & & & & & & & & \\
\hline T3.3 & & & & & & & & & & & & \\
\hline T3.4 & & & & & & & & & & & & \\
\hline T3.5 & & & & & & & & & & & & \\
\hline T3.6 & & & & & & & & & & & & \\
\hline T3.7 & & & & & & & & & & & & \\
\hline
\end{tabular}

Fig. 2. Expt 3: Diagrammatic representation of the sequence of LD changes imposed on the experimental groups T3.1 to T3.7 in relation to real calendar time. The temperature at which the animals were maintained was constant $17 \pm 1^{\circ} \mathrm{C}$ throughout. For each month of the treatment the daily LD cycle is indicated by the degree of shading as LD 16:8 'Long photophase' or LD 8:16 'Short photophase'

groups were relatively homogeneous in January shortly after the appearance of coelomic oocytes though some minor differences were detected; the most advanced group at this time was T3.3 but such minor differences as were detected are thought to be due to random differences within the expcrimental groups. The mean oocyte frequency in group T3.3 was only marginally greater than $100 \mu \mathrm{m}$ and in all other groups was less than this.

In March, the ranking order of the experimental groups as classified by the pooled oocyte diameter was dramatically different. The animals in experimental groups T3.7, T3.1 and T3.2 now had mean pooled
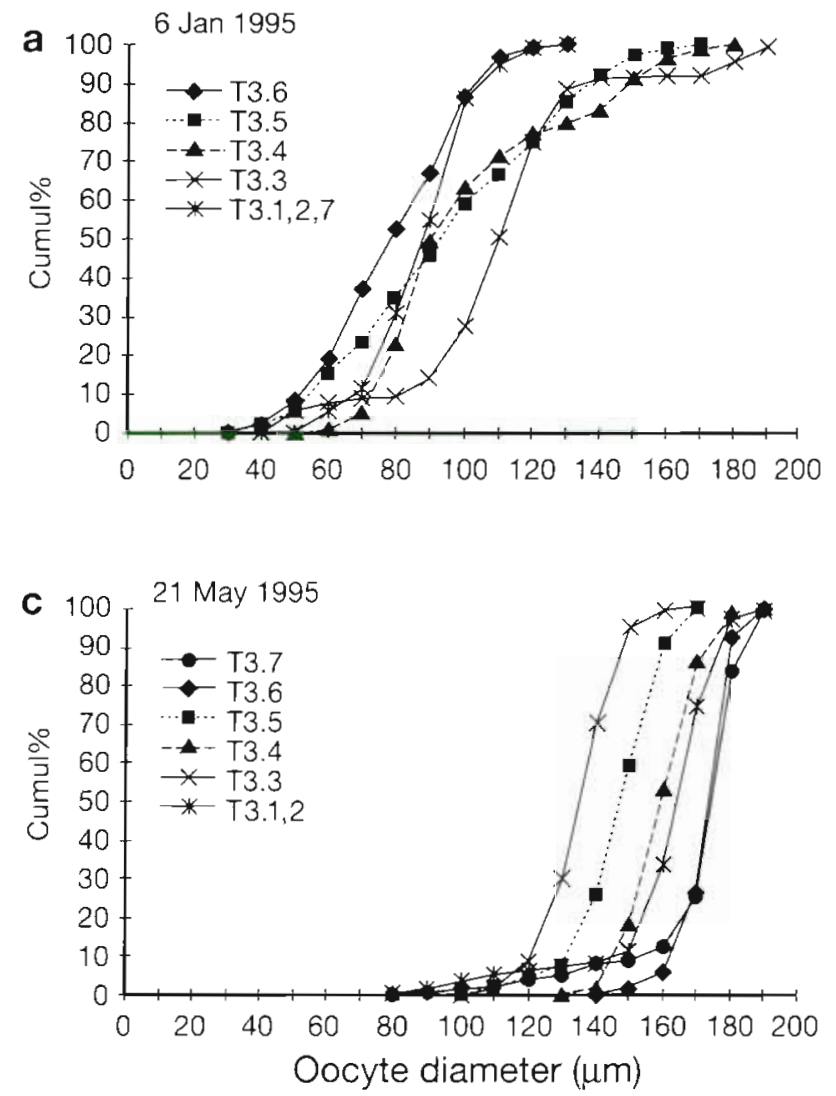

oocyte frequencies greater than $140 \mu \mathrm{m}$ (see Fig. 3b) whereas the mean oocyte diameter in T3.3 which in January had been the most advanced had remained less than $120 \mu \mathrm{m}$. At this time the animals in group T3.7 had the largest coelomic oocytes. By the time of the March sample animals in T3.3 had been exposed to LD 8:16 for $126 \mathrm{~d}$ and the 2 next most advanced groups (T3.1 and T3.2) had been exposed to LD 8:16 for $119 \mathrm{~d}$. In contrast, animals in group T3.5, which had the smallest oocytes, had been exposed only to LD 16:8, i.e. to continuous 'long' days.

The continuing influence of the LD cycle on the rate of oocyte growth was further confirmed by the results

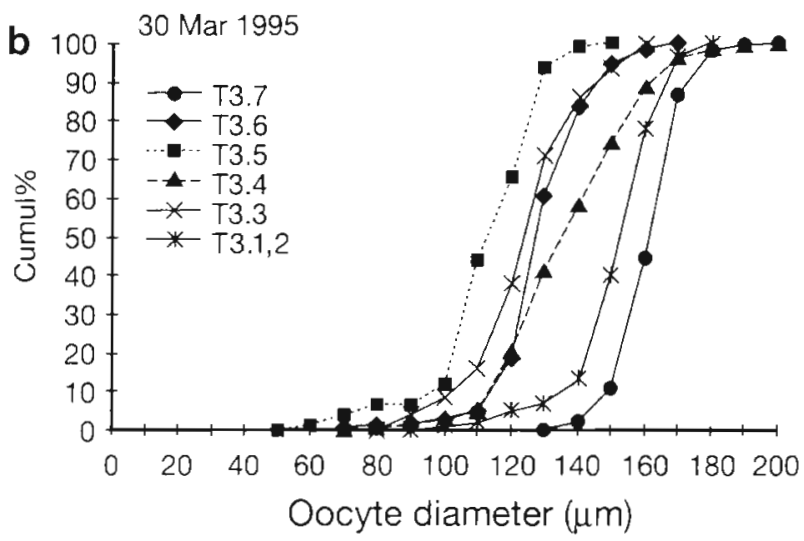

Fig. 3. Nereis (Neanthes) virens. Expt 3: Cumulative frequency distributions for the pooled oocyte samples obtained from the animals in each experimental treatment-T3.1 to T3.7 (see Fig. 2). The data are summarised for 3 sampling times: (a) January, (b) March and (c) May. The key shows the identity of the experimental groups. When the treatment of the individual groups had been the same at one of the sampling times a combined frequency distribution is shown. The sigmoid curve shows that the oocyte frequency distributions are distributed approximately normally. The method of presentation allows easy comparison of the mean oocyte diameter among the multiple treatment groups (intersection with the $50 \%$ line) and the degree of synchrony in a given frequency distribution 
Table 3. Nereis (Neanthes) virens. Expt 4: A posteriori analysis of the differences among means in the 7 treatments. The mean values are shown in rank order and means that were found to differ by less than the least significant range (SNK analysis) are underlined

\begin{tabular}{|lccccccc|}
\hline Rank order & 1 & 2 & 3 & 4 & 5 & 6 & 7 \\
Group no. & T3.3 & T3.5 & T3.1 & T3.2 & T3.4 & T3.7 & T3.6 \\
\hline Mean diameter & 136 & 149 & $\underline{156}$ & 162 & 160 & $\underline{170}$ & 172 \\
\hline
\end{tabular}

obtained in May (see Fig. 3c). By this time, group T3.6-which had experienced LD 16:8 only briefly at the beginning of the experiment-had in effect 'caught up with' group T3.7 that had been kept throughout in LD 8:16 and now had the slightly greater mean oocyte diameter. A full SNK analysis of the results is shown in Table 3 . This suggested that the oocyte growth rate was not greatly affected by the calendar time at which the various daylength transitions occurred nor the prior exposure to 'long' days as we had supposed it might have been. Rather, it seemed that the overall rate of growth over the period of the experiment was dependent only on the number of days during which the animals were exposed to the 2 different photoperiodic conditions LD 8:16 and LD 16:8.

This interpretation is confirmed by an analysis of the relationship between oocyte diameter at various times during the treatment cycle and the number of days' exposure to LD 8:16 that each treatment group had received. The correlation between the variables 'oocyte diameter' and 'average recorded oocyte growth rate' with the variable 'number of days exposed to LD 8:16' has been examined over the range of treatment times. The values of Pearson's correlation coefficient are summarised in Table 4 .

The relationship is essentially linear as shown in Fig. 4 where the mean oocyte diameter on 30 March 1995 is shown as a function of days' exposure to

Table 4. Nereis (Neanthes) virens. Expt 3: Evidence of the significant positive correlation between measures of oocyte growth, (1) mean oocyte diameter and (2) average instantaneous oocyte growth rate, and the cumulative number of LD 8:16 photoperiod cycles to which the animals had been exposed over the period indicated (see also Fig. 4)

\begin{tabular}{|c|c|c|}
\hline Variable & Period of examination & $\begin{array}{l}\text { Pearson's correlation } \\
\text { coefficient }\end{array}$ \\
\hline Oocyte diameter & 21 Nov 1994 to 30 Mar 1995 & $r=0.96(p<0.001)$ \\
\hline Oocyte diameter & 6 Jan 1995 to 21 May 1995 & $r=0.87(p<0.01)$ \\
\hline Oocyte diameter & 14 Feb 1995 to 21 May 1995 & $r=0.95(p<0.001)$ \\
\hline Oocyte growth rate & 6 Jan 1995 to 30 Mar 1995 & $r=0.9(p<0.001)$ \\
\hline Oocyte growth rate & 30 Mar 1995 to 21 May 1995 & $\mathrm{r}=0.52(0.1<\mathrm{p}<0.2)$ \\
\hline
\end{tabular}

LD 8:16. Oocyte growth rate and hence mean oocyte diameter is therefore independent of the calendar time when 'short' days are experienced and the results suggest that the external photoperiod is continuously consulted. It should be noted however that although the photoperiodic regime influences the rate of oocyte growth there is not an 'all or nothing' response. Some degree of oocyte growth occurred in all experimental treatments and, given time, gametogenesis can be completed even under conditions of constant LD 16:8 as also indicated by Expt 2.

\section{Expt 4: Effect of temperature on photoperiodically induced increase in oocyte growth}

Rationale. This experiment was designed to detect any synergism that might occur between the effects of the critical photoperiodic transition and the falling temperature regime that normally characterises the winter period. The development of the oocytes was monitored in 2 groups of animals maintained in the same photoperiod but in different temperature regimes. Female worms that had no oocytes larger than $100 \mu \mathrm{m}$ in diameter were selected at the end of January from a farm reared stock aged about $10 \mathrm{mo}$. They were transferred to LD $16: 8$ at a temperature of $17^{\circ} \mathrm{C}$ for $6 \mathrm{wk}$ to simulate summer conditions. The photoperiodic regime was then changed to LD 8:16 and 1 of 2 groups was exposed to a progressive reduction of temperature at $3^{\circ} \mathrm{C} \mathrm{mo}{ }^{-1}$ for $3 \mathrm{mo}$, i.e. March $13^{\circ} \mathrm{C}$, April $10^{\circ} \mathrm{C}$, May $7^{\circ} \mathrm{C}$. Coelomic biopsies were obtained from each group in March, April and May. The timing of the experiment was such that the response to transition from LD 16:8 to LD 8:16 in conjunction with declining temperature was being investigated during the early calendar summer.

Observations. The mean oocyte diameter for the animals from which the 2 groups were selected was $76 \mu \mathrm{m}$ in January at the start of the experiment. Oocyte growth was measured after exposure to a short simulated summer $\left(17 \pm 1^{\circ} \mathrm{C}\right.$ and LD 16:8) from coelomic biopsies taken at monthly intervals from March onwards. Oocyte growth was faster in those animals experiencing a declining temperature in conjunction with the transition to LD 8:16. The oocyte frequency distributions can be compared in Fig. 5; note that oocytes became substantially larger in treatment T4.2 and also became more uniform in size as is characteristic of sexually mature Nereidae (Olive \& Garwood 1981). 


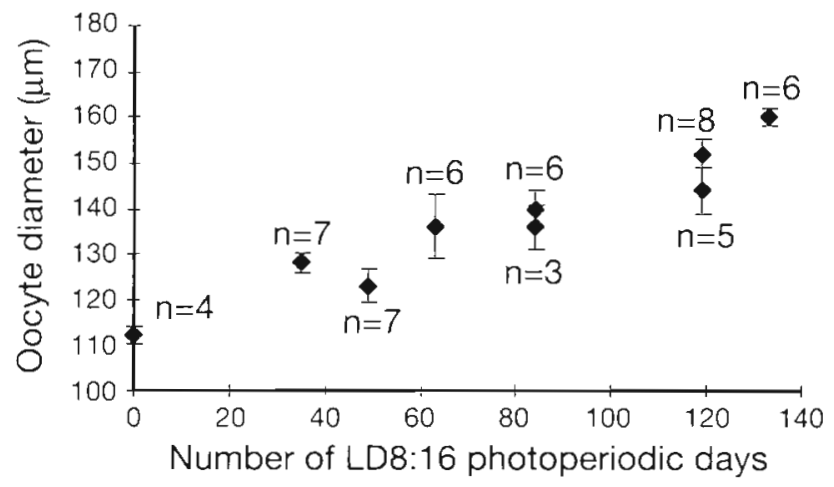

Fig. 4. Nereis (Neanthes) virens. Expt 3: Relationship between the mean oocyte diameter and number of 'short' LD 8:16 photoperiodic cycles experienced over a period of $139 \mathrm{~d}$ (January to March) in the sequence of treatments (see Fig. 2), Pearson correlation coefficient $\mathrm{r}=0.932, \mathrm{p}<0.001$. The mean represents the mean mean oocyte diameter, the vertical bars represent the standard deviation and n represents the number of animals sampled

\section{Expt 5: Modification of oocyte growth by endogenous factors related to age, condition and calendar time}

A number of experiments were conducted which reexamined the responses to static photoperiods and environmental temperature at different times of the year. A substantial number of experiments were carried out and only the most pertinent results will be presented here in summary form.

Expt 5a: Rationale. This treatment was designed to detect the possible influence of an exposure to LD 16:8 after earlier exposure to LD 8:16. The animals were selected in November at an age of 11 mo from a stock fertilised in advance of the natural breeding season in the previous year. Initial biopsies revealed that at the start of the experiment the animals either contained no free coelomic gametocytes or, if oocytes were present, none were larger than $100 \mu \mathrm{m}$ in diameter. The experiment was carried out at $12 \pm 1^{\circ} \mathrm{C}$ which, from the evidence of previous experiments, maximises the rate of oocyte development under LD 8:16 conditions. One group of the selected animals was maintained under LD 8.16 throughout whereas the second was subject to 2 pulses of long days LD 16:8.

Observations. The oocyte frequency distributions were initially unimodal with a modal diameter of $55 \mu \mathrm{m}$. The experimental animals included some that initially did not have coelomic oocytes, and in these, coelomic oocytes developed during the early part of the experiment, consequently by January the pooled oocyte frequencies were bimodal. By April the oocyte frequencies were again unimodal (modal diameter $190 \mu \mathrm{m})$ and were sufficiently mature to produce viable offspring. Oocyte maturation was neither de- layed nor accelerated by the pulses of LD 16:8. The rate of oogenesis was particularly rapid, which reflects the lower temperature at which the experiment was carried out (see also Expt 3).

Expt 5b: Rationale. The animals in this experiment treatment were maintained under LD 16:8 beyond the autumn equinox and were subsequently transferred to LD 8:16 during November, January and February while control animals were kept continuously under LD 16:8.

Observations. The animals transferred to LD 8:16 all responded to the transition and exhibited more rapid oocyte growth; the majority showed the characteristic cytological features of sexual maturity by April when they had achieved a mean diameter greater than
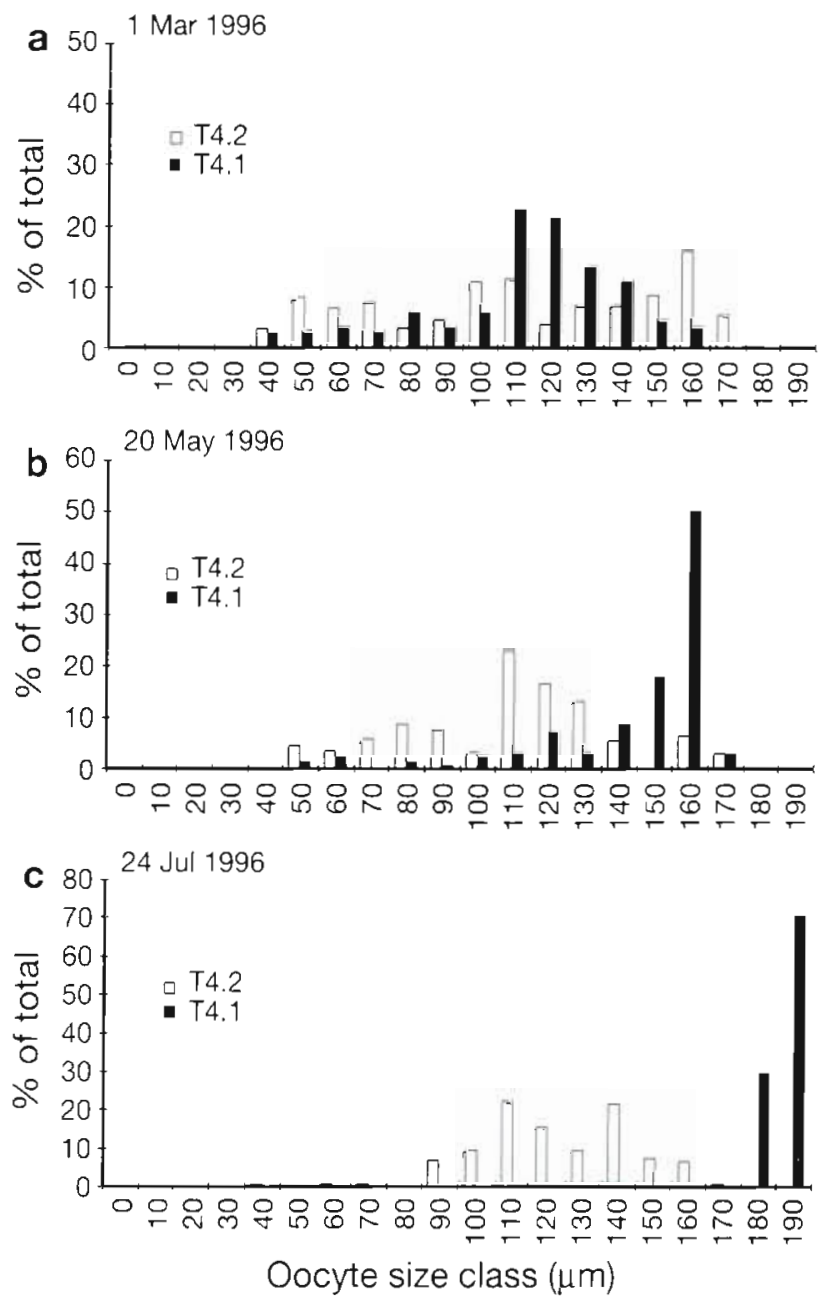

Fig. 5. Nereis (Neanthes) virens. Expt 4: Pooled oocyte frequency distributions from females in treatment groups T4.1 and T4.2 in March, May and July 1996. The data illustrate the synergism between falling environmental temperature and the photoperiodic response following transfer to LD 8:16. Animals in group T4.1 were subject to a declining temperature regime and in group $\mathrm{T} 4.2$ to constant $17 \pm 1^{\circ} \mathrm{C}$ 
$160 \mu \mathrm{m}$. In contrast the oocytes of animals kept under constant LD 16:8 developed more slowly. The relative frequency of animals categorised by the mean oocyte diameter is presented in Table 5.

In some of the animals under LD 16:8 (marked ${ }^{*}$ in Table 5) the oocytes initially continued to develop and by April their mean diameter was greater than $160 \mu \mathrm{m}$. The oocytes in these animals however became increasingly abnormal and additional small immature oocytes began to appear in the coelom. Eventually the larger oocytes regressed (oosorption), the newly proliferated oocytes in effect replacing them. Such animals appeared to have recycled the germ cells (see below for discussion of this in relation to the obligate semelparity of the group).

Expt 5c: Rationale. The experiment was initiated in February with animals that were 12 mo old. The objective was to investigate the effects of transient exposure to long days during the late winter/spring period. Two groups of animals were transferred to LD 16:8 from 7 February 1996 to 20 March 1996 and to 17 April 1996 prior to return to LD 8:16.

Observations. This experimental treatment was the only one of the many carried out where there was no obvious effect of static photoperiod. There were only very minor differences in oocyte growth rate between the individual treatments; in effect the control group held under constant LD 8:16 did not show the rapid oocyte growth that had previously been observed following similar experimental treatments. This is illustrated in Fig. 6 which shows the cumulative oocyte frequency curves for this experiment in comparison with data from Expt 4. Animals in Expt 5c appear not to have been physiologically competent to respond to the external (environmental) signal as was the case in Expt 4 (see further discussion below).

Table 5. Nereis (Neanthes) virens. Expt 5b: Frequency of animals in the defined oocyte diameter size ranges in the 4 experimental treatments. For the purposes of statistical comparison using the G-test approach the animals in the 3 treatment groups transferred to LD 8:16 have been combined. As at 22 April 1996 $G=10.62 \chi^{2 \text { crul(0.05:2) }}=5.99$. There is a significant degree of heterogenelty. As at 20 May $1996 G=75.1 \chi^{2}$ cmo.001.11 $=10.83$. There is a highly significant degree of heterogeneity between treatments

\begin{tabular}{|lcccc|}
\hline $\begin{array}{l}\text { LD 8:16 from } \\
\text { 26 Nov 1995 }\end{array}$ & $\begin{array}{c}\text { LD 8:16 from } \\
\text { 11 Jan 1996 }\end{array}$ & $\begin{array}{c}\text { LD 8:16 from } \\
\text { 19 Feb 1996 }\end{array}$ & $\begin{array}{c}\text { Continuous } \\
\text { LD 16:8 }\end{array}$ \\
\hline $\begin{array}{l}\text { Mean oocyte diameter at 22 Apr 1996 } \\
<120 \mu \mathrm{m}\end{array}$ & 0 & 1 & & \\
$120<x<160 \mu \mathrm{m}$ & 1 & 0 & 0 & 1 \\
$>160 \mu \mathrm{m}$ & 6 & 5 & 12 & $4^{*}$ \\
Mean oocyte diameter at 20 May 1996 & & & \\
$<160 \mu \mathrm{m}$ & 1 & 1 & 1 & 8 \\
$>160 \mu \mathrm{m}$ & 2 & 3 & 9 & 0 \\
\hline
\end{tabular}

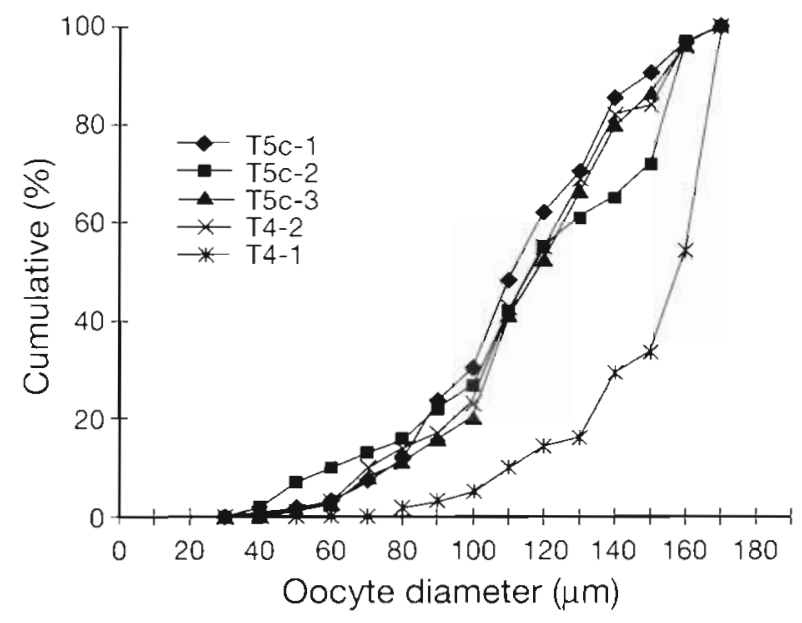

Fig. 6. Nereis (Neanthes) virens. Expts 4 \& 5c: Pooled cumulative oocyte frequency distributions for animals in Expts 4 \& 5c. Note that the oocytes of the animals in group T4-1 which were exposed to both lower temperature and LD 8:16 were substantially larger at the time of sampling than those from animals experiencing the LD 8:16 treatment without simultaneous reduction in temperature (Expt $5 \mathrm{c}$ \& $T 4-2$

\section{Expt 6: Effects of decerebration (hormone deprivation) on oocyte growth in comparison with the synergistic effects of photoperiod and temperature}

Rationale. Decerebration of Nereidae (at the appropriate stage of gametogenesis) can result in accelerated oocyte growth. This is thought to be because the supra-oesophageal ganglion is the source of a maturation inhibiting hormone (see Olive 1997 for review). In this experiment oocyte growth rates under different environmental conditions were compared with the accelerated oocyte growth induced by supraoesophageal ganglion extirpation.

Observations. The pooled mean oocyte diameter for the 4 experimental groups T6 1 to 4 are shown in Fig. 7 . Oocyte growth was most rapid in the decerebrate group and these animals became sexually mature and had died by September, only 4 mo after ganglion ablation. Animals experiencing LD 8:16 coupled with low temperature underwent the next most rapid gametocyte growth (cf. Expt 4, Fig. 5) and they were becoming mature (as evidenced by the cytological characteristics and uniform size of the oocytes) during September. The slowest rate of gametogenic development occurred in those animals kept in the photoperiod LD $16: 8$ and at $17 \pm 1^{\circ} \mathrm{C}$. Nevertheless 


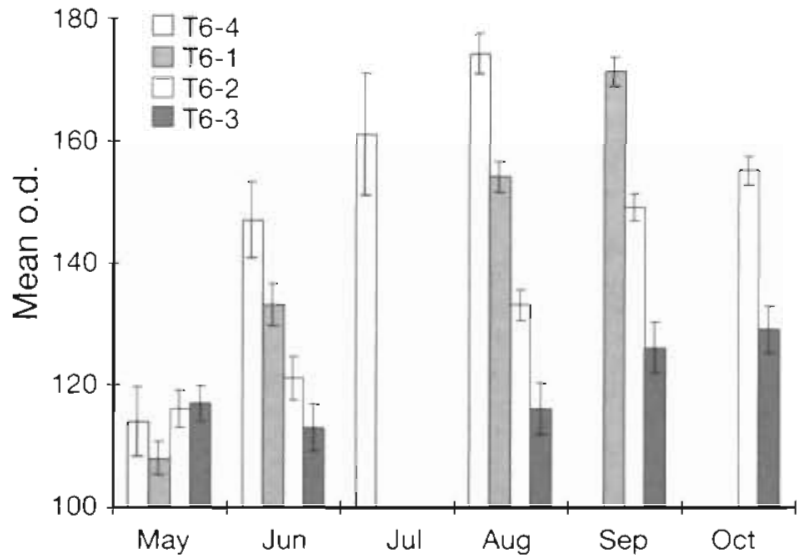

Fig. 7. Nereis (Neanthes) virens. Expt 6: Mean oocyte diameter $(\mu \mathrm{m})$ in the 4 experimental groups: T6.1-LD 8:16, cool seawater $\left(9^{\circ} \mathrm{C}\right) ; \mathrm{T} 6.2$ LD $8: 16$, warm sea water $\left(17^{\circ} \mathrm{C}\right)$; T6.3-LD 16:8, warm sea water; T6.4-decerebrated and LD $8: 16$, cool sea water $\left(9^{\circ} \mathrm{C}\right)$. The decerebrated group was the only one sampled in July because it was making far greater progress than the other groups. These animals had become mature and died by the time of the September sample. The vertical bars show the standard error to permit easy comparison of the means

even among these animals oocyte growth was not zero (see also Expts $2 \& 3$ ).

\section{Expt 7: Effects of age on the response to photoperiod and temperature}

Rationale. This experiment was essentially a mimic of earlier treatments but was carried out using more juvenile worms. At the onset of the experiment (November 1996) they were only 7 mo old (cf. 11 mo as in Expt 3) having developed from fertilisations carried out in May 1996. A relatively large number of animals was deployed in replicated sets of 35 juvenile animals exposed to each of the 3 photoperiod regimes at 2 constant temperatures. Since the animals did not have coelomic germ cells at the start of the experiment, some animals developed as males and others as females.

Observations. None of the animals proceeded through the rapid phase of oogenesis (nor became sexually mature males) during the course of the experimental treatments although individuals with small coelomic gametocytes began to appear from January onwards. The state of maturity of the surviving animals in all experimental groups on 20 April 1997 is summarised in Table 6.
The significance of this result lies in the absence of response to environmental factors known to stimulate oocyte development. We presume that the animals were below some necessary threshold of developmental competence that must be reached if a response to the environmental signals that normally initiate rapid oocyte growth is to be made.

\section{DISCUSSION}

\section{Photoperiodism and the onset of rapid oocyte growth}

Our results clearly establish that the external light dark cycle provides information that is involved in the regulation of oocyte growth rate in Nereis (Neanthes) virens. One of the characteristic features of photoperiodic responses of terrestrial organisms is the photoperiodic response curve (Saunders 1977) and we have constructed a preliminary response curve for $N$. virens by measuring the oocyte growth rate response to a series of static LD cycles with $\mathrm{T}=24$. The critical photoperiod appears to be associated with a $\mathrm{T}=24 \mathrm{LD}$ cycle between LD 12:12 and 13:11.

In the natural environment this transition occurs around the autumn equinox and will cause a change from a physiological state in which somatic growth and associated activities predominate (Olive \& Last unpubl.) to one in which more rapid oocyte growth takes place. A marked increase in oocyte growth rate in September was first noted by Brafield \& Chapman (1967) working in the Thames estuary (UK) and has been observed in the Netherlands (Fischer \& Hoeger 1993), on the northeast seaboard of the USA (Creaser \& Clifford 1982) and in the St. Lawrence estuary (Desrosiers et al. 1994). It seems reasonable to conclude that the photoperiodism revealed in our experiments with a cultured

Table 6. Nereis (Neanthes) virens. Expt 7: Frequency of juvenile (no coelomic gametes) male and female animals and mean oocyte diameter $(\mu \mathrm{m})$ in the female animals in replicate sets of animals maintained from the age of 7 mo under 3 different $L D$ cycles from. November 1996: T7.1, 6 wk exposure to LD 16:8; T7.2, 9 wk exposure to LD 16:8; and T7.3, direct transfer to LD 8.16. The results obtained on examination of each set of animals in the treatments dunng April 1997 are shown in the 2 rows of data for each treatment

\begin{tabular}{|c|c|c|c|c|c|c|c|}
\hline $\begin{array}{l}\text { T } \\
\text { Juv. }\end{array}$ & $\begin{array}{l}\text { empera } \\
\text { Moile }\end{array}$ & $\begin{array}{l}\text { ature } 17 \\
\text { Female }\end{array}$ & $\begin{array}{l} \pm 1^{\circ} \mathrm{C} \\
\text { Mean } \\
\text { diameter }\end{array}$ & $\begin{array}{l}\mathrm{T} \\
\text { Juv. }\end{array}$ & $\begin{array}{l}\text { emper } \\
\text { Male }\end{array}$ & $\begin{array}{l}\text { ature } 10 \\
\text { Female }\end{array}$ & $\begin{array}{l} \pm 1^{\circ} \mathrm{C} \\
\text { Mean } \\
\text { diameter }\end{array}$ \\
\hline $\begin{array}{ll}\text { T7.1, LD 16:8, } & 5 \\
6 w k & 6\end{array}$ & $\begin{array}{l}0 \\
2\end{array}$ & $\begin{array}{l}6 \\
7\end{array}$ & $\begin{array}{l}62 \\
60\end{array}$ & $\begin{array}{r}7 \\
11\end{array}$ & $\begin{array}{l}4 \\
8\end{array}$ & $\begin{array}{l}4 \\
4\end{array}$ & $\begin{array}{l}86 \\
69\end{array}$ \\
\hline $\begin{array}{l}\text { T7.2, LD 16:8, } \\
9 \text { wk }\end{array}$ & $\begin{array}{l}1 \\
0\end{array}$ & $\begin{array}{l}6 \\
6\end{array}$ & $\begin{array}{l}64 \\
60\end{array}$ & 6 & 1 & 0 & - \\
\hline $\begin{array}{ll}\text { T7.3, LD 8:16, } & 6 \\
\text { constant } & 9\end{array}$ & $\begin{array}{l}2 \\
4\end{array}$ & $\begin{array}{l}9 \\
7\end{array}$ & $\begin{array}{l}76 \\
62\end{array}$ & 13 & 3 & 4 & 82 \\
\hline
\end{tabular}


population is also operating as a component of the seasonal timing of natural populations.

Responses to the external photoperiod have been reported in a substantial variety of marine invertebrates (see Chu \& Levin 1989), being implicated in the control of seasonal reproduction in several classes of Crustacea-amphipods, copepods, decapods (Waddy \& Aiken 1992), 2 classes of Echinoidea - asteroids and echinoids - and Tunicata (Bingham 1997), but has not been as fully investigated as it has in terrestrial organisms. A number of studies, such as those summarised by Waddy \& Aiken (1992), emphasise the importance of interactions between photoperiodic effects and other environmental factors which also influence gametogenic processes (notably temperature) and which modify the responses made to changes in photoperiod. Understanding of these interactions is necessary to properly interpret the importance of photoperiodism in marine animals.

A critical photoperiod has only previously been established for 1 other polychaete, the iteroparous scale worm Harmothoe imbricata where 2 separate photoperiodic mechanisms are involved, each with its own characteristic critical daylength. A transition to long photophase days in the spring stimulates rapid oocyte growth (Garwood \& Olive 1982, Clark 1988), the critical daylength being between LD 10:14 and 11:13. A second photoperiodic effect stabilises oogenic growth; oosorption will occur in female $H$. imbricata during the winter unless they experience $42 \mathrm{~d}$ in which the photophase in a $24 \mathrm{~h} \mathrm{LD}$ cycle is less than $13 \mathrm{~h}$ (Clark 1988). The response to static fixed LD cycles was the same as to progressively changing LD cycles (Olive 1985), and time is measured from the critical point in a changing sequence of daylengths. Elements of circannual rhythmicity can also be detected in the gametogenic cycle of $H$. imbricata and a hierarchical sequence of events has been revealed in the control of the overall reproductive cycle (Olive et al. 1990).

Other studies of photoperiodic effects in marine invertebrates have been based on the interpretation of the responses of organisms to progressively changing photoperiodic regimes with a phase change (often $6 \mathrm{mo}$ ) in relation to the subjective solar year. The results of such experiments may be difficult to interpret without knowledge of the critical daylength. The characteristic sine wave form of the changing solar daylength is in effect transformed to a rectilinear form by photoperiodic responses with a critical daylength. For Harmothoe imbricata the transformed photoperiodic year is asymmetrical with critical transitions occurring early in February and in late August but for Nereis (Neanthes) virens the transformed photoperiodic cycle will be approximately symmetrical with important transitions occurring at the autumn and spring equinox periods.
Fong \& Pearse (1992a, b) have shown an influence of photoperiod on the time of breeding in Neanthes limnicola (Johnston), a viviparous and a self-fertilising hermaphrodite (Smith 1950) that is, like other Nereidae, semelparous. Reproduction is annually modular, with parturition occurring in 1 yr old animals in the late spring/summer period. Seasonally changing photoperiod has an effect on the time of parturition and in effect controls the lifespan which may be 6 to 8 or 12 to 14 mo according to the time of birth and the photoperiodic regime under which the animals are reared from birth. Animals born in the fall (autumn) after photoperiodic manipulation and subsequently reared under ambient conditions reproduce in the ambient spring. Those born at the same time, but reared under 'out-of-phase' photoperiods (i.e. long days), require some 12 to 14 mo to reach maturity and they become mature during the following fall (autumn)

If Neanthes limnicola, like Nereis (Neanthes) virens, has a critical response to daylength at about LD 12:12, exposure to photoperiods in which the photophase is greater than the critical value (or scotophase shorter than the criticall will inhibit oocyte growth and this must increase the lifespan of these semelparous organisms. Cassai (unpubl. data), working in our laboratories, has shown that oocyte growth rate in Perinereis rullieri is significantly greater under long photophase (LD 16:8) than under short photophase (LD 8:16) conditions while Fong (1991) found no discernible effect of photoperiod on oocyte growth rate in Nereis succinea.

\section{Evidence for continuous consultation of the external photoperiod}

During the course of the experiments, we exposed Nereis (Neanthes) virens to different photoperiodic regimes at various times of the year and in nearly all cases detected a clear response. This was especially clear in Expt 3 where the overall rate of oocyte growth over an extended period of time was strongly influenced by the number of days in which the photophase in the $24 \mathrm{~h}$ LD cycle was greater or less than the critical value. This result implies that the animals respond to the photoperiod on a daily basis and that the changing photoperiod does not operate an irreversible trigger between one physiological state and another.

\section{Moderation of the photoperiodic response-effects of temperature and calendar time}

Long term biological rhythms with properties similar to the circadian system have been implicated in the life 
cycles of a variety of organisms. Saunders $(1977,1978)$ pointed out the significance of the observations of Blake (1959) on the long term clock-like control of eclosion in some insects and this model has been used as a basis for understanding long term biological rhythmicity in the eclosion-like 'epitoky' of Nereidae.

In the first clear demonstration of circa-lunar rhythmicity, Hauenschild $(1955,1960)$ showed that the free running period of the overt cycle of sexual maturation of Platynereis dumerilii differed from that of the exogenous lunar cycle and that the biological cycle could be entrained to a lunar periodicity ( $29.5 \mathrm{~d}$ ) by exposure to periods of 'light at night' which was thus acting as a zeitgeber to the endogenous cycle. Olive \& Garwood (1983) suggested that the annual pattern of reproduction in Nereis (Hediste) diversicolor may be controlled in an analogous way. Oocyte growth rate in that species is temperature compensated in the range 5 to $20^{\circ} \mathrm{C}$ and an overt cyclc of reproduction at the population level is expressed in populations maintained for 2 or more years under constant temperature and daylength (Olive 1981, Olive \& Garwood 1983), More recently Fong \& Pearse (1992a) have suggested that the seasonal cycle of Neanthes limnicola could also be an expression of a circa-annual rhythm of reproduction reset by the external photoperiod. The concept has developed therefore that cyclic reproduction in Nereidae is the expression of a gated rhythmic process in which reproduction occurs as a 'once-only' event comparable with the circadian rhythm of eclosion in dipteran insects (see Olive 1984 for discussion). This hypothesis is not incompatible with the operation of the continuously consulted photoperiodic input we have described for Nereis (Neanthes) virens but the relative importance of the 2 components may be different between species. In $N$. virens the expression of any free running circannual rhythm could only be observed in the absence of clear photoperiodic and/or temperature inputs

During the subjective autumn and winter Nereis (Neanthes) virens make a clear oocyte growth response to the transfer to 'short' days provided that they have reached some necessary state of development or physiological condition. The response is expressed even if they are at a temperature of $17^{\circ} \mathrm{C}$ which is well above the seasonal normal. Sometimes however (as in Expt 4) exposure to LD 8:16 only induces rapid oocyte growth if the animals also experience a reduction in temperature. In the NE UK surface waters, maximum seawater temperatures occur only shortly before the autumn equinox and there is then a progressive reduction in temperature. The phase delay between the photoperiodic cycle and the annual temperature cycle also increases with depth. Consequently in the natural environment the autumn equinox is associated with relatively warm water but the temperature subsequently declines. The experimental observations suggest that there is a synergism between the effects of the photoperiodic transition and exposure to lower temperature and sometimes both environmental inputs are necessary to induce rapid oocyte growth outside those seasons when oocyte growth would normally occur.

A similar synergism between photoperiodic inputs and environmental temperature was observed for the hesionid Kefersteinia cirrata (Olive \& Pillai 1983) and has been particularly well studied in the American lobster Homarus americanus where studies of the environmental control of seasonal reproduction carried out with the view to permit effective broodstock management revealed a complex interaction between photoperiodic inputs and the temperature cycle (Aiken \& Waddy 1989). At low temperatures the maturation system is regulated by temperature but at elevated temperatures the photoperiodic effect becomes more dominant. Furthermore the responses to artificial changes in environmental conditions (photoperiod and/or temperature) of $H$. americanus are, like those we have described in Nereis (Neanthes) virens, modified by real calendar time (Waddy \& Aiken 1992). Although the reproductive cycles and life histories of these animals are very different, it has in both cases been possible to devise systems of manipulation to induce spawning and sexual maturation throughout the year (see 'Acknowledgements').

\section{Endocrine transduction of the environmental signals}

In Nereidae, oogenesis is inhibited by secretion(s) of the supra-oesophageal ganglion and the level of inhibition is progressively reduced during sexual maturation by a reduction in the titer of circulating hormone(s) (for reviews of the earlier literature see Fischer 1984, Dhainaut 1984, Fischer \& Rabien 1986 , Olive 1997); transduction of the environmental signal may therefore involve changes in endocrine activity. Production and/or release of the inhibitory cerebral hormone is inhibited in maturing females (Porchet \& Cardon 1976, Porchet et al. 1979, 1989) and the whole system is in effect a 'positive feedback' system in which developing oocytes come to suppress the production of the hormone(s) that inhibit their further development. This culminates in a normally irreversible transition to the fully mature state. This system, though certainly not fully understood, does have properties which seem particularly well adapted to the semelparous mode of reproduction that characterises this family (Golding \& Olive 1978, Golding 1985, 1987 , Golding \& Yuwono 1994). Exposure to LD 8:16 and 
lower temperature have the same effect as hormonal deprivation by decerebration (Expt 6) and it seems reasonable to suppose that the effects of environmental manipulation are to reduce the levels of production of hormones by the endocrine system.

A substantial component of the oocyte yolk protein is synthesised by a class of coelomic cells - the éléocytes - which cluster around the developing oocytes (Fischer 1979, Fischer \& Dhainaut 1985, Fischer \& Rabien 1986, Baert \& Slomianny 1987) and transfer yolk precursor molecules to the developing oocytes (Fischer \& Hoeger 1993). There is therefore a secretion-transport-uptake system involved in the accumulation of yolk proteins by the oocytes of Nereidae and the photoperiodic oocyte growth respond must be mediated via this system. The evidence discussed by Fischer \& Hoeger (1993) suggests that there is a slow, receptor mediated, uptake mechanism in which measured titers of vitellogenin in the coelomic fluid are normally more than sufficient to saturate the vitellogenin receptor protein (Fischer et al. 1991) so that it is likely that one of the target cells involved in the signal transduction is the oocyte itself.

\section{Seasonality and the semelparous life cycle}

In the majority of marine animals seasonal reproduction is exhibited as a component of an iteroparous life cycle but in some groups, notably all members of the polychaete family Nereidae (Annelida) and all higher Cephalopoda (Mollusca), the pattern of reproduction is strictly semelparous yet reproduction may also be strongly seasonal. The regulation of these life cycles poses particular problems when the average life span is greater than 1 yr because the seasonal reproductive event occurs in only a part of the population. Nereidae are mostly not short lived species, as is generally supposed to be the case for semelparous organisms (Pianka 1970, Roff 1992, Stearns 1992). Nereis (Neanthes) virens is indeed one of the largest and potentially longest lived of the marine annelids (Olive et al. 1998) and, as in most Nereidae, the generation time is greater than the phase length of the breeding cycle. Therefore the proportion of sexually mature worms in the population at the time of breeding will be less than unity as observed in natural populations of $N$. virens (Snow \& Marsden 1974, Creaser et al. 1983, Olive 1993). The mean generation time is itself a response to environmental factors and in $N$. virens is decreased under intensive culture. High growth rate reduces both the generation time and the mean size at maturity, consequently there is an inverse relationship between growth rate and size at maturity (Olive et al. 1986,1998$)$.
Environmental factors therefore have 2 separate roles in the control of seasonal reproduction in Nereidae: (1) regulation of the physiological state leading to the onset of sexual maturation and (2) regulation of the time at which sexual maturation begins and ends. In this study, we have concentrated on the factors which control the time of onset of sexual maturation but have also provided evidence of the factors that modify this process. We have used populations of cultured animals but believe that the same mechanisms operate in natural conditions.

A model of the semelparous life cycle of Nereidae is now emerging. During the pre-maturation phase of the life cycle which, in a long lived species such as Nereis (Neanthes) virens, will be several years, the animals will be exposed to oscillations in conditions which suppress or encourage gametogenesis. Initially the responses to this oscillation will be covert and will not culminate in marked changes in the state of sexual maturity. Eventually the animals will become reproductively competent and females will undergo rapid oogenesis while experiencing short (i.e. photophase $<12 \mathrm{~h})$ LD cycles and low temperature. The return of long photophase conditions and warm temperature before completion of gametogenic development will tend to arrest this process unless the animals have reached a sufficient stage of sexual development that internal factors (such as the negative feedback from the coelomocytes) have permanently suppressed cerebral hormone activity. In this way a strong element of seasonal synchrony is imposed on the overt expression of sexual maturity at the population level.

Under the non-constrained conditions of commercial culture most individuals have become competent to complete the life cycle and become sexually mature within 1 yr but seasonality will still be imposed by natural photoperiodic LD cycles. In natural populations where the life cycle is longer (Olive et al. 1998) it is possible that the animals proceed through a series of photoperiod induced changes in metabolic activity but that the overt oocyte growth rate response to short photoperiods is suppressed until the animals become competent to complete gametogenesis. Thus a covert annual cycle of physiological activity may underlie the once per lifetime transition to sexual maturity.

Acknowledgements. The authors thank the British Council for support given to A. Djunaedi as part of the Indonesian Marine Sciences Education Project and the Directors of Seabait Ltd for permission to refer to work carried out with the support of the Department of Trade and Industry. Information presented in this publication has been incorporated into procedures for the manipulation of the time of breeding of marine annelids as applied to commercial culture for use as sea angling bait and other purposes. A patent application has been filed by Seabait Ltd. Requests for information about the 
patented procedures and requests to use the processes under license should be addressed to: The managing director, Seabait Ltd, Woodhorn Village, Ashington, Northumberland NE63 9NW, United Kingdom or sent via e-mail at pcowin@ seabait.ace.com.

\section{LITERATURE CITED}

Aiken DE, Waddy SL (1989) The interaction of temperature and photoperiod in the regulation of spawning by American lobsters (Homarus americanus). Can J Fish Aquat Sci 46:145-148

Baert JL, Slomianny MC (1987) Heterosynthetic origin of the major yolk protein, vitellin, in a Nereid, Perinereis cultrifera (Polychaete Annelid). Comp Biochem Physiol B 88 : 1191-1199

Bass NB, Brafield AB (1972) The life cycle of the polychaete Nereis virens. J Mar Biol Assoc UK 52:701-726

Bentley MG. Pacey AA (1992) Physiological and environmental control of reproduction in polychaetes. Oceanogr Mar Biol Annu Rev 30:443-481

Bingham BL (1997) Light cycles and gametogenesis in three temperate ascidian species. Invertebr Biol 116:61-70

Blake GM (1959) Control of diapause by an internal clock in Anthrenus verbasci (L.). Nature 183:126-127

Brafield AE, Chapman G (1967) Gametogenesis and breeding in a natural population of Nereis virens. J Mar Biol Assoc UK 47:619-627

Caron A, Desrosiers G, Retiere C, Hudier E (1993) Comparison of demographic parameters relating to natural populations of the polychaete Nereis virens (Sars) and Nephtys caeca (Fabricius). Oceanol Acta 16:403-412

Chu JW, Levin L (1989) Photoperiod and temperature regulation of growth and reproduction in Streblospio benedicti (Polychaeta: Spionidae). Int J Invertebr Reprod Dev 15: 31-142

Clark RB (1961) The origin and formation of the heteronereis. Biol Rev Camb Phil Soc 36:211-255

Clark S (1988) A two phase photoperiodic response controlling the annual gametogenic cycle in Harmothoe imbricata (L). Invertebr Reprod Dev 14:245-266

Creaser EP, Clifford DA (1982) Life history studies of the sandworm Nereis virens in the sheepscote estuary, Maine. Fish Bull 80:735-743

Creaser EP, Clifford DA, Hogan MJ, Sampson DB (1983) A commercial sampling programme for sandworms Nereis virens Sars and bloodworms Glycera dibranchiata Ehlers, harvested along the Maine coast. NOAA Tech Rep NMFS SSRF-767, p 1-56

Desrosiers G, Caron A, Olivier M, Miron G (1985) Cycle de développement d'une population de Nereis virens (Polychaeta: Nereidae) sur la rive sud de l'estuaire maritime du Saint Laurent. Oceanol Acta 17:178-190

Desrosiers G, Caron A, Olivier M, Miron G (1994) Life history of the Polychaete Nereis virens (Sars) in an intertidal flat of the lower St-Lawrence estuary. Oceanol Acta 17: $683-695$

Dhainaut A (1984) Oogenesis in polychaetes-ultrastructural differentiation and metabolism of nereid oocytes. Fortschr Zool 29:183-205

Djunaedi A (1995) Environmental regulation of oocyte growth rates in Nereis virens (Annelida: Polychaeta). MPhil thesis, University of Newcastle upon Tyne

Fischer A (1979) A vitellogenin-like antigen in the coelomic fluid of maturing Nereis virens females. Naturwissenschaften $66: 316$
Fischer A (1984) Control of oocyte differentiation in nereids (Annelida, Polychaeta)-facts and ideas. Fortschr Zool 29. $227-245$

Fischer A, Dhainaut A (1985) The origin of yolk in the oocytes of Nereis virens (Annelida, Polychaeta)-electron-microscopic and autoradiographic studies by use of unspecific and yolk-specific markers. Cell Tissue Res 240:67-76

Fischer A, Hoeger U (1993) Metabolic links between somatic sexual maturation and oogenesis in nereid annelids--a brief review. Invertebr Reprod Dev 23:131-138

Fischer A, Rabien H (1986) Molecules and cellular functions driving oocyte growth in nereid annelids. In: Porchet $M$ (ed) Advances in invertebrate reproduction 4. Elsevier Science Publishers, Amsterdam, p 195-205

Fischer A, Rabien H, Heacox AE (1991) Specific, concentration dependent uptake of vitellin by the oocytes of Nereis virens in vitro. J Exp Zool 260:106-115

Fong PP (1991) Environmental control of reproduction in Californian Nereidae (Annelida: Polychaeta). Doctoral Dissertation, University of California (Santa Cruz)

Fong PP, Pearse JS (1992a) Evidence for a programmed circannual life cycle modulated by increasing daylengths in Neanthes Imnicola (Polychaeta: Nereidde) from central California. Biol Bull 182:289-297

Fong PP, Pearse JS (1992b) Photoperiodic regulation of parturition in the self fertilising viviparous polychaete Neanthes limnicola from central California. Mar Biol 112:81-89

Garwood PR, Olive PJW (1982) The influence of photoperiod on oocyte growth and its role in the control of the reproductive cycle of the polychaete Harmothoe imbricata. Int J Invertebr Rep Dev 5:161-166

Golding DW (1985) Brain body interactions in Nereis-reactivation of the cerebral neuro-endocrine system by experimental manipulation. Int J Invertebr Rep Dev 8:51-59

Golding DW (1987) Brain body interactions in Nereis-deactivation of the cerebral neuro-endocrine system by ganglion transplantation. Int J Invertebr Rep Dev 12:281-293

Golding DW, Olive PJW (1978) Patterns of regenerative growth, reproductive strategy and endocrine control in polychaete annelids. In: Gaillard PJ, Boer HH (eds) Comparative endocrinology. Elsevier/North Holland, Amsterdam, p 117-120

Golding DW, Yuwono E (1994) Latent capacities for gametogenic cycling in the semelparous invertebrate Nereis. Proc Natl Acad Sci USA 91:11777-11781

Hauenschild C (1955) Photoperiodizität als Ursache des von Mondphase-abhängigen Metamorphose-Rhythmus bei dem Polychaeten Platynereis dumerilii. Z Naturforsch B 11:658-622

Hauenschild C (1960) Lunar periodicity. Cold Spring Harbor Symp Quant Biol 25:491-497

Olive PJW (1981) Environmental control of reproduction in Polychaeta: experimental studies of littoral species in NE England. In: Clark WH. Adams TS (eds) Advances in invertebrate reproduction. 2. Elsevier North Holland, Amsterdam, p 37-52

Olive PJW (1984) Environmental control of reproduction in Polychaeta. Fortschr Zool 29:17-38

Olive PJW (1985) Physiological adaptations and the concepts of optimal reproductive strategy and physiological constraint in marine invertebrates. In: Laverack MS (ed) Physiological adaptations of marine animals, Vol 39. Symposia of the Society for Experimental Biology. Society of Experimental Biology, Cambridge, p 268-300

Olive PJW (1993) Management of the exploitation of the lugworm Arenicola marina and the ragworm Nereis virens (Polychaeta) in conservation areas. Aquat Conserv 3:1-24 
Olive PJW (1994) Polychaeta as a world resource: a review of patterns of exploitation as sea angling baits and the potential for aquaculture based production. Mem Mus Natl Hist Nat 162:603-610

Olive PJW (1997) Annelida-Polychaeta. In: Adams TS (ed) Reproductive biology of invertebrates, Vol 8. Oxford and IBH Publishing Co. Pvt. Ltd, New Delhi, p 153-189

Olive PJW, Clark S, Lawrence A (1990) Global warming and seasonal reproduction: perception and transduction of environmental information. In: Hoshiyo $M$ (ed) Advances in invertebrate reproduction, Vol 5. Elsevier Science Publishers (Biomedical Division), Amsterdam, p 265-270

Olive PJW, Garwood PR (1981) Gametogenic cycle and population structure of Nereis (Hediste) diversicolor and Nereis (Nereis) pelagica from northeast England. J Mar Biol Assoc UK 61:193-213

Olive PJW, Garwood PR (1983) The importance of long term endogenous rhythms in the maintenance of reproductive cycles of marine invertebrates-a reappraisal. Int $J$ Invertebr Reprod 6:339-347

Olive PJW, Grant A, Cowin PBD (1986) Decision and choice in polychaete reproductive cycles. In: Porchet $M$ (ed) Advances in invertebrate reproduction, Vol 4. Elsevier, Amsterdam, p 371-378

Olive PJW, Pillai G (1983) Reproductive biology of the polychaete Kefersteinia cirrata Keferstein (Hesionidae). 2. The gametogenic cycle and evidence for photoperiodic control of oogenesis. Int J Invertebr Reprod 6:307-315

Olive PJW, Rees S, Cadman P, Desrosiers G, Fletcher J (1998) Interactions of environmental temperature with photoperiod in determining age specific reproductive effort in semelparous Polychaeta. J Therm Biol 22:489-497

Editorial responsibility: Otto Kinne (Editor),

Oldendorf/Luhe, Germany
Pianka ER (1970) On r- and K-selection. Am Nat 104:592-597

Porchet M, Baert JL, Dhainaut A (1989) Evolution of the concepts of vitellogenesis in polychaete annelids. Invertebr Reprod Dev 16:53-61

Porchet M, Cardon C (1976) The inhibitory feed-back mechanism coming from oocyte and acting on brain endocrine activity in Nereidae. Gen Comp Endocrinol 30:378-390

Porchet M. Dhainaut A, Porchet-Hennere E (1979) Evidence of coelomic substances inducing genital maturation during natural oogenesis of Perinereis cultrifera. Wilhelm Roux Arch 186:129-137

Roff DA (1992) The evolution of life histories. Chapman and Hall, New York

Saunders DS (1977) An introduction to biological rhythms Blackie, London

Saunders DS (1978) Insect clocks. Pergamon Press, London

Schroeder PC, Hermans CO (1975) Annelida:Polychaeta. In: Giese AC, Pearse JS (eds) Reproduction of marine invertebrates, Vol 3. Academic Press, New York, p 1-213

Smith RI (1950) Embryonic development in the viviparous nereid polychaete, Neanthes lighti Hartman. J Morph 87 : $414-466$

Snow DR, Marsden JR (1974) Life cycle, weight and possible age distribution in a population of Nereis virens from New Brunswick. J Nat Hist 8:513-527

Sokal RR, Rohlf FJ (1995) Biometry, 3rd edn. WH Freeman and Company, New York

Stearns SC (1992) The evolution of life histories. Oxford University Press, Oxford

Waddy SL, Aiken DE (1992) Environmental intervention in the reproductive processes of the American lobster, Homarus americanus. Invertebr Reprod Dev 22:245-252

Submitted: June 17, 1998; Accepted: July 9, 1998

Proofs received from author(s): October 2, 1998 